ISSN. 2775-4324 (Online)

Journal of Physical Activity and Sports

Volume 2, Nomor 3, Bulan 2021, 375-386

Journal of Physical Activity and Sports

\title{
Pengaruh Circuit Training Terhadap Kekuatan Fisik Pada Atlet \\ Sekolah Sepakbola (SSB) Persisac Semarang
}

\author{
Umar Fitriadi $^{1}$, Galih Dwi Pradipta ${ }^{2}$, Yulia Ratimiasih ${ }^{3}$ \\ umarfitriadi04@gmail.com ${ }^{1}$, galihdwipradifta@upgris.ac.id ${ }^{2}$, ratimiasihyulia@gmail.com \\ Universitas PGRI Semarang
}

Received: 4 Juni 2021; Revised: 30 Desember 2021; Accepted: 31 Desember 2021

\begin{abstract}
Circuit Training is a form of training in which there are various movements that are carried out together and continuously and are limited by rest at each exchange of training forms with circuit training there will be many positive shifts in basic skills and also simultaneously restore physical fitness, muscle ability, endurance, dexterity and flexibility of the body. Strength needs to be given special attention from the coach so that the achievements of the SSB (Football School) Persisac Semarang do not decline.

The research used in this study is "One-Groups Pretest-Posttest Design". The sample in this study was football athletes SSB Persisac Semarang. The sampling technique was purposive sampling of 15 players. Retrieval of data using instruments that have been used, with the pre-test and post test.

Based on the results of the t test, the $t$ value (31.281)> t table (1.761) was obtained, and the p value <0.05. This result means that Ho is accepted, so the hypothesis states that there is an effect of Circuit Training training on increasing the physical strength of football school students at SSB Persisac Semarang.
\end{abstract}

Keywords: Circuit Training, Football, Strength

\begin{abstract}
Abstrak
Circuit Training merupakan bentuk latihan yang didalamnya terdapat berbagai gerakan yang dilakukan secara bersama sama dan berkesinambungan dan dibatasi oleh istirahat pada setiap pertukaran bentuk latihan dengan adanya latihan sirkuit akan banyak peralihan peralihan yang positif pada keahlian dasar dan juga memulihkan secara sekaligus kesegaran fisik, kemampuan otot, ketahanan, ketangkasan dan keluwesan tubuh. Kekuatan perlu di perhatikan khusus dari pelatih agar prestasi SSB (Sekolah Sepak bola) Persisac Semarang tidak menurun. Penelitian digunakan dalam penelitian ini adalah "One-Groups Pretest-Posttest Design". Sample dalam penelitian ini atlet sepakbola SSB Persisac Semarang. Teknik pengambilan sampel ini adalah purposive sampling 15 pemain. Pengambilan data menggunakan instrumen yang sudah pernah di gunakan, dengan adanya pre-test dan post test.

Berdasarkan hasil uji t diperoleh nilai t hitung $(31,281)>\mathrm{t}$ tabel $(1,761)$, dan nilai $\mathrm{p}<$ dari 0,05 . Hasil tersebut diartikan Ho diterima, sehingga hipotesisnya menyatakan ada pengaruh latihan Circuit Training terhadap peningkatan kekuatan fisik siswa sekolah sepakbola di SSB Persisac Semarang.
\end{abstract}

Kata kunci : Circuit Training, Sepakbola, Kekuatan 


\section{PENDAHULUAN}

Berolahraga ialah aktivitas raga yang memiliki watak game serta berisi perjuangan melawan diri sendiri ataupun dengan orang lain ataupun konfrontasi dengan unsur- unsur alam. Sebutan berolahraga dikala ini tidak asing lagi untuk warga. Berolahraga bisa dimaksud selaku kebutuhan yang ialah sesuatu aktivitas manusia yang mau hidup sehat, baik jasmanio ataupun rohaninya. Bagi Apri Agus( 2012: 22) tujuan orang olahraga antara lain buat tingkatkan derajat kesehatan, buat tingkatkan kebugaran jasmani, buat tamasya, buat menggapai prestasi serta buat pembelajaran. Menggapai tujuan berolahraga tersebut tidaklah hal- hal yang gampang dicoba pada berolahraga prestasi, perihal ini memerlukan pembinaan yang sungguh- sungguh dari seluruh pihak yang dicoba secara berjenjang serta berkepanjangan. Bersumber pada kutipan diatas bisa dimengerti kalau pembinaan serta kenaikan prestasi berolahraga membutuhkan perencanaan pelatih yang matang, terprogram serta berkesinambungan. Dapat disimpulkan bahwa olahraga merupakan melakukan suatu aktivitas atau kegiatan untuk meningkatkan kualitas diri seseorang secara jasmani dan rohani untuk mencapai sebuah prestasi. Di Indonesia pada saat ini olahraga sudah merupakan kegiatan yang paling digemari oleh masyarakat luas, salah satu cabang olahraga yang paling digemari yaitu sepakbola.

Menurut Undang-Undang Republik indonesia, (2005:3) Keolahragaan nasional adalah keolahragaan yang berdasarkan pancasila dan Undang-Undang Dasar Negara Republik Indonesia tahun 1945 yang berakar pada nilai-nilai keolahragaan, kebudayaan nasional indonesia, dan tanggap terhadap tuntunan perkembangan olahraga, pembinaan olahraga merupakan suatu usaha untuk mengembangkan potensi atlet sehingga dapat meningkatkan prestasi. Beraneka ragam jenis olahraga yang terlah tersebar di Indonesia salah satunya yaitu sepakbola yang sangat pesat perkembangannya di dunia maupun di Indonesia. Perkembangan olahraga sepakbola menyebar ke daerah-daerah Indonesia, termasuk daerah Jawa Tengah salah satunya kota Semarang yang memiliki banyak sekolah sepakbola (SSB). Dari sekian banyak SSB yang ada peneliti memilih Persisac Semarang karena peneliti sudah melakukan pengamatan secara mandiri bahwa Persisac memiliki potensi yang besar namun memang kondisi kekuatan fisik atlet perlu ditingkatkan. Hal tersebut membuat peneliti tertarik untuk melakukan treatment circuit training untuk SSB Persisac Semarang.

Sepakbola dapat diartikan sebagai permainan yang sangat menentang secara fisik dan psikis, karena seorang pemain perlu menampilkan keterampilan masing-masing dibawah kondisi permainan waktu yang minim, dan dapat mencermati berbagai pergantian-pergantian situasi permainan dengan cepat. Menjadi seorang pemain sepakbola yang baik memerlukan kondisi fisik diantaranya; daya ledak, ketepatan, kecepatan, kelincahan, kekuatan, koordinasi, keseimbang an dan kelenturan. Kondisi fisik tersebut yang sangat berpengaruh besar dalam performa atlet saat bertanding ialah daya tahan. Daya tahan yakni suatu unsur mendasar dan penting yang sangat 
diperlukan dalam aktivitas sehari-hari. Daya tahan dapat diartikan sebagai kemampuan untuk beroperasi, berlatih dengan waktu yang panjang tanpa adanya rasa kelelahan yang lebih Indrayana (2012:4) Pemain diwajibkan memiliki kondisi fisik yang baik pada saat bertanding maupun saat latihan. Dalam olahraga aerobik salah satunya sepakbola ketahanan tubuh sangatlah penting. Di dalam olahraga aerobik selalu berkaitan dengan bagaimana meningkatan stamina, tenaga, elastisitas tubuh, kegesitan gerak-gerik tubuh. Khasan dkk (2012:162) Meningkatkan prestasi olahraga merupakan salah satu upaya untuk meningkatkan tingkat kecerdasan nasional, dan kecerdasan sangat penting untuk meningkatkan taraf hidup bangsa Indonesia. Berusaha selalu untuk berprestasi melalui pembelajaran dan pelatihan di sekolah dan klub sepak bola. Popularitas sepak bola tidak hanya untuk masyarakat luas, tetapi juga milik dunia intelektual, yang dibuktikan dengan banyaknya buku-buku yang ditulis oleh para ilmuwan olahraga dan penelitian tentang pelatih, pelatih dan ilmu-ilmu pendukung lainnya yang berkaitan dengan sepak bola. Kondisi fisik, teknik, taktik, mentalitas, pembinaan, sarana dan prasarana, kondisi atlet, gizi dan banyak faktor lainnya semuanya berkontribusi dalam peningkatan prestasi. Kondisi fisik menjadi faktor utama pencapaian olahraga. Dalam sepakbola, kondisi fisik menjadi faktor utama. Kemampuan kondisi fisik yang prima dalam permainan sepakbola sangat berguna untuk mempraktekan teknik dan taktik. Permainan sepakbola modern dibutuhkan kemampuan kondisi fisik yang optimal untuk dapat bermain dalam tempo tinggi selama 2 x 45 menit. Salah satu kondisi fisik yang penting dimiliki oleh seorang pemain sepakbola adalah kekuatan. Menurut Syafruddin (2011 :141) Berdasarkan pengamatan observasi saya ketika mengikut latihan atau disaat pertandingan dalam ajang turnamen antar (SSB) Sekolah sepakbola seKota Semarang SSB Persisac Semarang kondisi fisik nya masih belum stabil dilihat dari para atlet yang mudah kelelahan saat dalam pertandingan. Hal tersebut sangat mempengaruhi prestasi atlet sehingga diperlukan kondisi fisik yang kuat dan oleh karena itu diperlukannya latihan kekuatan fisik circuit training pada pemain. Peran olahraga di dalam kehidupan sangatlah penting sangat sulit untuk memisahkan olahraga dengan kehidupan modern saat ini, dalam meningkatkan prestasi atau menjaga kesehatan tubuh. Salah satu cara memelihara kekebalan tubuh kita adalah melakukan olahraga dengan teratur dan intensif. Olahraga merupakan aktivitas yang mengakibatkan terjadinya gerakan pada seluruh organ tubuh sehingga jantung merasa terbebani dan terpacu dengan cepat. Lesmana (2014:373)

Melihat kenyataan ini kekuatan fisik perlu perhatian khusus dari pelatih agar prestasi SSB Persisac Semarang tidak semakin menurun. Pelatih harus tahu factor-faktor yang mempengaruhi kemampuan kekuatan, agar dalam menyusun program latihan tidak salah buat. Banyak faktor yang mempengaruhi kemampuan kekuatan seorang pemain sepakbola. Salah satu dari beberapa komponen tersebut kapasitasnya rendah, maka akan mempengaruhi tingkat VO2max karena masingmasing komponen tersebut saling mendukung satu dengan yang lainnya, oleh karena itu perlu diadakan penelitian tentang pengaruh metode latihan Circuit Training yang akan di terapkan atau di ajarkan dalam pembinaan sekolah sepakbola (SSB) Persisac Semarang. Diharapkan dengan adanya 
penelitian Pengaruh latihan Circuit Training terhadap kekuatan fisik pada sekolah sepakbola (SSB) persisac semarang mampu menunjang prestasi atlet maupun club.

\section{METODE PENELITIAN}

Penelitian ini merupakan penelitian eksperimental semu, yang melibatkan studi kausalitas. Menurut (Suharsimi Arikunto 2013: 272) penelitian eksperimental adalah untuk mengetahui dampak tindakan atau perlakuan tertentu terhadap subjek penelitian. Rancangan penelitian yang digunakan dalam penelitian ini adalah "group of pre-test-post-test design". Rancangan penelitian diprediksikan untuk menentukan keadaan awal sebelum menerima perlakuan, dan post-test untuk memahami keadaan setelah perlakuan, sehingga dapat Mengetahui lebih akurat karena dapat dibandingkan dengan kondisi sebelum mendapat pengobatan (Sugiyono, 2014: 110). Menurut Sugiyono (2014: 117), populasi adalah suatu wilayah yang digeneralisasikan, terdiri dari objek atau topik dengan jumlah dan ciri tertentu yang ditentukan oleh peneliti, kemudian diteliti dan diringkas. Populasi yang digunakan dalam penelitian ini adalah Pemain sepakbola SSB Persisac Semarang. Jumlah atlet pada SSB Persisac Semarang sebanyak 25 atlet.

Menurut (Arikunto, 2013:174) "Sampel adalah sebagian atau wakil populasi yang diteliti, sampel adalah bagian dari jumlah dan karakteristik yang dimiliki oleh populasi tersebut. Teknik pengambilan sampel ini adalah purposive sampling, sampel diambil dengan maksud atau tujuan tertentu. Berdasarkan pengertian diatas maka sampel pada penelitian ini berjumlah 15 orang. Adapun syarat-syarat 15 atlet tersebut adalah sebagai berikut, yaitu:

a. Pemain SSB Persisac Semarang yang masih aktif mengikuti program latihan rutin yang sudah ditentukan oleh managemen 3 (kali) latihan dalam seminggu adapun pada saat hari sabtu-minggu ada uji coba sparing partner dalam kota maupun luar.

b. Tidak dalam keadaan sakit.

c. Pemain yang mengikuti Liga Pelajar Kota Semarang

Teknik pengumpulan data pada penelitian ini menggunakan teknik tes dan pengukuran. Menurut Widiastuti (2011) Instrumen yang digunakan untuk mengambil data pre-test dan post test dalam penelitian ini menggunakan 2 item tes.

Teknik pengumpulan data dalam penelitian ini menggunakan Tes dan pengukuran. Setelah diberikan pre-test kemudian kelompok eksperimen diberi treatment berupa latihan sirkuit dengan frekuensi 3 kali seminggu selama 12 kali pertemuan, Menurut Tjaliek Sugiardo dalam jurnal Kartika Dwi Kusumawati (2016:4) Praktik 12 hingga 16 kali telah mengalami perubahan permanen. Program latihan keliling setiap atlet diharuskan melakukan tugas yang telah ditentukan pada setiap posisi yang terdiri dari 6 posisi, dan sesuai dosis yang ditentukan, melakukan tes pasca eksperimen pada terapis kelompok eksperimen selama 12 kali pertemuan, dan hasil yang diperoleh adalah sebelum tes Bandingkan dengan setelah tes. Data yang dikumpulkan dalam penelitian ini adalah data pre-test 
sebelum sampel menjalani treatment, dan data post-test setelah sampel menjalani circuit training. Uji validitas merupakan prosedur uji isi instrumen yang bertujuan untuk mengukur ketelitian instrumen yang digunakan dalam penelitian (Sugiyono, 2014: 206). Pengujian reliabilitas instrumen dapat dilakukan secara eksternal atau internal. Secara eksternal dapat dilakukan dengan pengujian ulang (stabilitas), pengujian ekivalensi dan pengujian gabungan (Sugiyono, 2014:183).

Data yang diperoleh tiap-tiap tes merupakan data kasar dari hasil tiap tes yang dicapai pemain. Agar data tersebut mempunyai arti maka diperlukan pengolahan dan analisis data secara statistika data SPSS. Sebelum analisis data untuk mengetahui pengaruh latihan sirkuit untuk meningkatkan kekuatan fisik. Terlebih dahulu diperlukan uji prasyarat, yang meliputi uji normalitas, uji homogenitas dan uji hipotesis

\section{HASIL DAN PEMBAHASAN}

Peneliti melakukan penelitian dengan melampirkan perijinan pada pihak sekolah sepak bola (SSB) dengan melampirkan surat ijin penelitian yang diterbitkan oleh Universitas PGRI Semarang dengan nomor surat 696/AM/FPISKR/XII/2020. Setelah itu peneliti melakukan pendekatan dengan pemilik dan pelatih, dan menentukan waktu untuk melakukan pre test, treatment dan post test selama $12 \mathrm{x}$ pertemuan.

Pada penelitian ini dilakukan Pretest pada pertemuan pertama dan Posttest pada pertemuan terakhir, adapun jadwal pertemuan tersebut adalah sebagai berikut :

Tabel 4.1 Waktu Penelitian

\begin{tabular}{|c|l|c|}
\hline No & \multicolumn{1}{|c|}{ Waktu } & Keterangan \\
\hline 1 & Rabu, 23 Desember 2020 & Pre Test dan Treatment \\
\hline 2 & Jumat, 25 Desember 2020 & Treatment \\
\hline 3 & Minggu, 27 Desember 2020 & Treatment \\
\hline 4 & Rabu, 30 Desember 2020 & Treatment \\
\hline 5 & Jumat, 1 Januari 2021 & Treatment \\
\hline 6 & Minggu, 3 Januari 2021 & Treatment \\
\hline 7 & Rabu, 6 Januari 2021 & Treatment \\
\hline 8 & Jumat, 8 Januari 2021 & Treatment \\
\hline 9 & Minggu, 10 Januari 2021 & Treatment \\
\hline 10 & Rabu, 13 Januari 2021 & Treatment \\
\hline 11 & Jumat, 15 Januari 2021 & PostTest dan Treatment \\
\hline 12 & Minggu, 17 Januari 2021 \\
\hline
\end{tabular}

\section{Kekuatan Fisik Pada Sekolah Sepakbola (SSB) PERSISAC Semarang (Pretest)}

Tabel 4.2 Hasil Pretest

\begin{tabular}{|c|l|c|c|c|c|c|}
\hline \multirow{2}{*}{ No } & \multirow{2}{*}{ Nama } & \multicolumn{5}{|c|}{ Item Tes (1 Menit) } \\
\cline { 3 - 7 } & & $\begin{array}{c}\text { Shuttle } \\
\text { Run }\end{array}$ & Push Up & Back Up & Sit Up & $\begin{array}{c}\text { Squat } \\
\text { Jump }\end{array}$ \\
\hline 1 & ZDS & 8 & 29 & 31 & 33 & 32 \\
\hline 2 & FF & 7 & 26 & 33 & 31 & 38 \\
\hline 3 & FB & 8 & 33 & 26 & 30 & 31 \\
\hline
\end{tabular}




\begin{tabular}{|c|l|l|l|l|l|l|}
\hline 3 & DMM & 8 & 31 & 33 & 29 & 30 \\
\hline 5 & EW & 9 & 32 & 31 & 28 & 32 \\
\hline 6 & FM & 9 & 27 & 27 & 31 & 33 \\
\hline 7 & NH & 8 & 29 & 31 & 27 & 30 \\
\hline 8 & RK & 7 & 25 & 29 & 31 & 37 \\
\hline 9 & PM & 7 & 23 & 31 & 33 & 25 \\
\hline 10 & AP & 8 & 25 & 29 & 30 & 33 \\
\hline 11 & MID & 9 & 28 & 31 & 32 & 28 \\
\hline 12 & DS & 7 & 30 & 33 & 35 & 36 \\
\hline 13 & GA & 9 & 26 & 29 & 31 & 35 \\
\hline 13 & VA & 8 & 28 & 31 & 33 & 38 \\
\hline 15 & MPP & 8 & 29 & 30 & 31 & 33 \\
\hline
\end{tabular}

Hasil penelitian data pretest kekuatan fisik siswa sekolah (SSB) PERSISAC Semarang diperoleh diperoleh nilai minimal sebesar 119; nilai maksimal 141; rata-rata (mean) sebesar 130,13; nilai tengah (median) sebesar 130 modus sebesar 125; dan simpangan baku (standar deviasi) sebesar 5,436.

\section{Kekuatan Fisik Pada Sekolah Sepakbola (SSB) PERSISAC Semarang (Posttest)}

Tabel 4.3 Hasil Post-test

\begin{tabular}{|c|l|c|c|c|c|c|}
\hline \multirow{2}{*}{ No } & \multirow{2}{*}{ Nama } & \multicolumn{5}{|c|}{ Item Tes (1 Menit) } \\
\cline { 3 - 7 } & & $\begin{array}{c}\text { Shuttle } \\
\text { Run }\end{array}$ & Push Up & Back Up & Sit Up & $\begin{array}{c}\text { Squat } \\
\text { Jump }\end{array}$ \\
\hline 1 & ZDS & 13 & 54 & 55 & 49 & 44 \\
\hline 4 & FF & 16 & 50 & 54 & 51 & 59 \\
\hline 5 & FB & 15 & 56 & 49 & 55 & 41 \\
\hline 4 & DMM & 14 & 55 & 55 & 47 & 54 \\
\hline 5 & EW & 16 & 48 & 49 & 51 & 58 \\
\hline 6 & FM & 13 & 54 & 48 & 49 & 44 \\
\hline 7 & NH & 14 & 49 & 54 & 55 & 58 \\
\hline 8 & RK & 15 & 48 & 46 & 55 & 41 \\
\hline 9 & PM & 15 & 49 & 55 & 48 & 59 \\
\hline 10 & AP & 15 & 54 & 55 & 54 & 44 \\
\hline 11 & MID & 13 & 48 & 54 & 49 & 59 \\
\hline 14 & DS & 14 & 56 & 48 & 51 & 57 \\
\hline 15 & GA & 13 & 50 & 54 & 48 & 41 \\
\hline 14 & VA & 14 & 49 & 55 & 48 & 40 \\
\hline 15 & MPP & 16 & 51 & 54 & 47 & 59 \\
\hline
\end{tabular}

Hasil penelitian data pretest kekuatan fisik siswa sekolah (SSB) PERSISAC Semarang diperoleh diperoleh nilai minimal sebesar 205; nilai maksimal 230; rata-rata (mean) sebesar 219,13; nilai tengah (median) sebesar 222 modus sebesar 206; dan simpangan baku (standar deviasi) sebesar 9,078.

\section{Uji Normalitas}

Kriteria yang digunakan untuk mengetahui normal tidaknya suatu sebaran adalah jika P > 0,05 tabel sebaran dinyatakan normal, dan jika $\mathrm{P}<0,05$ tabel sebaran dikatakan tidak normal. Hasil uji normalitas penelitian ini dapat dilihat pada tabel berikut:

Tabel 4.4 Hasil Uji Normalitas

\begin{tabular}{|l|l|l|l|l|}
\hline & Df & P & Sig & Keterangan \\
\hline
\end{tabular}




\begin{tabular}{|l|l|l|l|l|}
\hline Pretest & 15 & 0,200 & 0,05 & Normal \\
\hline Posttest & 15 & 0,042 & 0,05 & Normal \\
\hline
\end{tabular}

\section{Uji Homogenitas}

Kriteria yang digunakan untuk mengetahui homogen tidaknya suatu sebaran adalah jika P > 0,05 tabel sebaran dinyatakan normal, dan jika $\mathrm{P}<0,05$ tabel sebaran dikatakan tidak normal. Hasil uji homogenitas penelitian ini dapat dilihat pada tabel berikut:

Tabel 4.5 Hasil Uji Homogenitas

\begin{tabular}{|l|c|c|c|c|}
\hline & Df & P & Sig & Keterangan \\
\hline Pretest-Posttest & 15 & 0,01 & 0,05 & Homogen \\
\hline
\end{tabular}

\section{Uji t (Paired Sample T test)}

Uji t dilakukan untuk mengetahui ada tidaknya pengaruh latihan Circuit Training terhadap peningkatan kekuatan fisik siswa sekolah sepakbola di SSB Persisac Semarang. Uji t hasilnya dapat dilihat pada tabel berikut:

Tabel 4.6 Hasil Uji Hipotesis (Uji t)

\begin{tabular}{|l|c|c|c|c|c|}
\hline Pretest-Posttest & Df & T tabel & T hitung & P & Keterangan \\
\hline Kekuatan Fisik & 14 & 1,761 & 31,281 & 0,000 & Ada Pengaruh \\
\hline
\end{tabular}

Berdasarkan hasil uji t diperoleh nilai t hitung $(31,281)>\mathrm{t}$ tabel $(1,761)$, dan nilai $\mathrm{p}<$ dari 0,05 . Hasil tersebut diartikan Ho diterima, sehingga hipotesisnya menyatakan ada pengaruh latihan Circuit Training terhadap peningkatan kekuatan fisik siswa sekolah sepakbola di SSB Persisac Semarang.

Adapun hasil uji t tiap komponen kondisi fisik adalah sebagai berikut:

\section{a. Shuttle Run}

Tabel 4.7 Hasil Pre Test dan Post Test Shuttle Run

\begin{tabular}{|c|l|c|c|}
\hline \multirow{2}{*}{ No } & \multirow{2}{*}{ Nama } & \multicolumn{2}{|c|}{ Dalam waktu 1 Menit } \\
\cline { 3 - 4 } & & Pre Test & Post Test \\
\hline 1 & ZDS & 8 & 13 \\
\hline 2 & FF & 7 & 16 \\
\hline 3 & FB & 8 & 15 \\
\hline 3 & DMM & 8 & 14 \\
\hline 5 & EW & 9 & 16 \\
\hline 6 & FM & 9 & 13 \\
\hline 7 & NH & 8 & 14 \\
\hline 8 & RK & 7 & 15 \\
\hline 9 & PM & 7 & 15 \\
\hline 10 & AP & 8 & 15 \\
\hline 11 & MID & 9 & 13 \\
\hline 12 & DS & 7 & 14 \\
\hline 13 & GA & 9 & 13 \\
\hline 13 & VA & 8 & 14 \\
\hline 15 & MPP & 8 & 16 \\
\hline
\end{tabular}




\begin{tabular}{|c|c|c|c|c|c|}
\hline Pre-Post & Df & T tabel & T hitung & P & Keterangan \\
\hline Shuttle Run & 14 & 1,761 & 15,544 & 0,000 & Ada Pengaruh \\
\hline
\end{tabular}

Berdasarkan hasil uji t diperoleh nilai t hitung $(15,544)>\mathrm{t}$ tabel $(1,761)$, dan nilai $\mathrm{p}<$ dari 0,05 .

Hasil tersebut diartikan bahwa latihan shuttle run dalam Circuit Training berpengaruh terhadap peningkatan kekuatan fisik pada sekolah sepakbola (SSB) PERSISAC Semarang.

b. Push Up

. Tabel 4.9 Hasil Pre Test dan Post Test Push Up

\begin{tabular}{|c|l|c|c|}
\hline \multirow{2}{*}{ No } & \multirow{2}{*}{ Nama } & \multicolumn{2}{|c|}{ Dalam waktu 1 Menit } \\
\cline { 3 - 4 } & & Pre Test & Post Test \\
\hline 1 & ZDS & 29 & 54 \\
\hline 2 & FF & 26 & 50 \\
\hline 3 & FB & 33 & 56 \\
\hline 3 & DMM & 31 & 55 \\
\hline 5 & EW & 32 & 48 \\
\hline 6 & FM & 27 & 54 \\
\hline 7 & NH & 29 & 49 \\
\hline 8 & RK & 25 & 48 \\
\hline 9 & PM & 23 & 49 \\
\hline 10 & AP & 25 & 54 \\
\hline 11 & MID & 28 & 48 \\
\hline 12 & DS & 30 & 56 \\
\hline 13 & GA & 26 & 50 \\
\hline 13 & VA & 28 & 49 \\
\hline 15 & MPP & 29 & 51 \\
\hline
\end{tabular}

Tabel 4.10 Hasil SPSS Push Up

\begin{tabular}{|c|c|c|c|c|c|}
\hline Pre-Post & Df & T tabel & T hitung & P & Keterangan \\
\hline Push Up & 14 & 1,761 & 27,857 & 0,000 & Ada Pengaruh \\
\hline
\end{tabular}

Berdasarkan hasil uji t diperoleh nilai t hitung $(27,857)>t$ tabel $(1,761)$, dan nilai $\mathrm{p}<$ dari 0,05 .

Hasil tersebut diartikan bahwa latihan Push up dalam Circuit Training berpengaruh terhadap peningkatan terhadap kekuatan fisik pada sekolah sepakbola (SSB) PERSISAC Semarang.

c. Back Up

Tabel 4.11 Hasil Pre Test dan Post Test Back Up

\begin{tabular}{|c|l|c|c|}
\hline \multirow{2}{*}{ No } & \multirow{2}{*}{ Nama } & \multicolumn{2}{|c|}{ Dalam waktu 1 Menit } \\
\cline { 3 - 4 } & & Pre Test & Post Test \\
\hline 1 & ZDS & 31 & 55 \\
\hline 2 & FF & 33 & 54 \\
\hline 3 & FB & 26 & 49 \\
\hline 3 & DMM & 33 & 55 \\
\hline 5 & EW & 31 & 49 \\
\hline 6 & FM & 27 & 48 \\
\hline 7 & NH & 31 & 54 \\
\hline 8 & RK & 29 & 46 \\
\hline 9 & PM & 31 & 55 \\
\hline 10 & AP & 29 & 55 \\
\hline 11 & MID & 31 & 54 \\
\hline 12 & DS & 33 & 48 \\
\hline
\end{tabular}




\begin{tabular}{|l|l|l|l|}
\hline 13 & GA & 29 & 54 \\
\hline 13 & VA & 31 & 55 \\
\hline 15 & MPP & 30 & 54 \\
\hline
\end{tabular}

Tabel 4.12 Hasil SPSS Back Up

\begin{tabular}{|c|c|c|c|c|c|}
\hline Pre-Post & Df & T tabel & T hitung & P & Keterangan \\
\hline Push Up & 14 & 1,761 & 27,338 & 0,000 & Ada Pengaruh \\
\hline
\end{tabular}

Berdasarkan hasil uji t diperoleh nilai $t$ hitung $(27,338)>\mathrm{t}$ tabel $(1,761)$, dan nilai $\mathrm{p}<$

dari 0,05. Hasil tersebut diartikan bahwa latihan back up dalam Circuit Training berpengaruh terhadap peningkatan kekuatan fisik pada sekolah sepakbola (SSB) PERSISAC Semarang.

d. Sit Up

Tabel 4.13 Hasil Pre Test dan Post Test Sit Up

\begin{tabular}{|c|l|c|c|}
\hline \multirow{2}{*}{ No } & \multirow{2}{*}{ Nama } & \multicolumn{2}{|c|}{ Dalam waktu 1 Menit } \\
\cline { 3 - 4 } & & Pre Test & Post Test \\
\hline 1 & ZDS & 33 & 49 \\
\hline 2 & FF & 31 & 51 \\
\hline 3 & FB & 30 & 55 \\
\hline 3 & DMM & 29 & 47 \\
\hline 5 & EW & 28 & 51 \\
\hline 6 & FM & 31 & 49 \\
\hline 7 & NH & 27 & 55 \\
\hline 8 & RK & 31 & 55 \\
\hline 9 & PM & 33 & 48 \\
\hline 10 & AP & 30 & 54 \\
\hline 11 & MID & 32 & 49 \\
\hline 12 & DS & 35 & 51 \\
\hline 13 & GA & 31 & 48 \\
\hline 13 & VA & 33 & 48 \\
\hline 15 & MPP & 31 & 47 \\
\hline
\end{tabular}

Tabel 4.14 Hasil SPSS Sit Up

\begin{tabular}{|c|c|c|c|c|c|}
\hline Pre-Post & Df & T tabel & T hitung & P & Keterangan \\
\hline Push Up & 14 & 1,761 & 17,851 & 0,000 & Ada Pengaruh \\
\hline
\end{tabular}

Berdasarkan hasil uji t diperoleh nilai t hitung $(17,851)>\mathrm{t}$ tabel $(1,761)$, dan nilai $\mathrm{p}<$ dari 0,05. Hasil tersebut diartikan bahwa latihan sit up dalam Circuit Training berpengaruh terhadap peningkatan kekuatan fisik pada sekolah sepakbola (SSB) PERSISAC Semarang.

e. Squat Jump

Tabel 4.15 Hasil Pre Test dan Post Test Squat Jump

\begin{tabular}{|c|l|c|c|}
\hline \multirow{2}{*}{ No } & \multicolumn{2}{|c|}{ Nama } & \multicolumn{2}{|c|}{ Dalam waktu 1 Menit } \\
\cline { 3 - 4 } & & Pre Test & Post Test \\
\hline 1 & ZDS & 32 & 44 \\
\hline 2 & FF & 38 & 59 \\
\hline 3 & FB & 31 & 41 \\
\hline 3 & DMM & 30 & 54 \\
\hline 5 & EW & 32 & 58 \\
\hline
\end{tabular}




\begin{tabular}{|c|l|c|c|}
\hline 6 & FM & 33 & 44 \\
\hline 7 & NH & 30 & 58 \\
\hline 8 & RK & 37 & 41 \\
\hline 9 & PM & 25 & 59 \\
\hline 10 & AP & 33 & 44 \\
\hline 11 & MID & 28 & 59 \\
\hline 12 & DS & 36 & 57 \\
\hline 13 & GA & 35 & 41 \\
\hline 13 & VA & 38 & 40 \\
\hline 15 & MPP & 33 & 59 \\
\hline
\end{tabular}

Tabel 4.16 Hasil SPSS Squat Jump

\begin{tabular}{|c|c|c|c|c|c|}
\hline Pre-Post & Df & T tabel & T hitung & P & Keterangan \\
\hline Push Up & 14 & 1,761 & 6,659 & 0,000 & Ada Pengaruh \\
\hline
\end{tabular}

Berdasarkan hasil uji $t$ diperoleh nilai $t$ hitung (6.659)> t tabel (1.761), dan $\mathrm{p}<0.05$. Hasil

penelitian ini menunjukkan bahwa latihan squat jump pada circuit training berpengaruh terhadap peningkatan kekuatan fisik Sekolah Sepak Bola Persisac Semarang (SSB). Kondisi fisik merupakan kemampuan seseorang dalam memahami kemampuannya dalam mendukung aktivitas fisik. Kesehatan jasmani sangat penting bagi kehidupan manusia terutama sebagai seorang olahragawan khususnya sepak bola. Kondisi fisik merupakan faktor utama pemain sepak bola, dan kondisi fisik menjadi dasar utama sebelum pemain sepak bola memasuki tahapan teknik, taktis dan mental. Oleh karena itu, diperlukan teknik dan metode latihan yang efektif untuk memperbaiki kondisi fisik pemain sepak bola, salah satunya adalah latihan touring. Pelatihan tur merupakan salah satu bentuk pelatihan yang dapat dilakukan dalam satu babak, dan selama satu putaran itu terdapat beberapa pos, pada setiap pos itu peserta melakukan tugas. Seperti latihan bersinambungan, dalam latihan sirkuit dapat dilakukan variasi latihan. Pada penelitian ini dilakukan 12x pertemuan untuk pengambilan pretest, pemberian treatment selama $12 \mathrm{x}$ pertemuan kemudian pengambilan posttest. Pemberian treatment pada siswa sekolah sepakbola (SSB) persisac semarang yaitu 8x Shuttle Run, 15x Push Up, 15x Back Up, 15x Sit Up dan 15x Squat Jump. Dalam rangkaian treatment tersebut dilakukan pada pos-pos dan diakumulasi dalam waktunya. Pada 12x pertemuan mengalami kenaikan dan penurunan hasil. Setelah pemberian treatment selesai, maka dilakukan posttest. Pada penelitian ini hasil posttest menunjukan adanya perubahan.

Berdasarkan hasil uji t diperoleh nilai t hitung (31.281)> nilai t tabel (1.761), dan nilai $p<0.05$. Hasil ini berarti hipotesis diterima, sehingga hipotesis menunjukkan bahwa circuit training berpengaruh terhadap kekuatan fisik Sekolah Sepakbola Semarang Semarang (SSB). Ini karena pelatihan touring meliputi pelatihan kekuatan, daya tahan, daya ledak, fleksibilitas, koordinasi, ketangkasan, kecepatan, reaksi, dan keseimbangan. Melalui latihan berkelanjutan semacam ini, beban tubuh akan terbiasa dengan latihan, sehingga kondisi fisik menjadi terlatih dan menjadi lebih baik. Hal terpenting dalam latihan adalah intensitas latihan yang terus menerus.Didukung dengan frekuensi latihan yang terus menerus secara 
otomatis akan meningkatkan intensitas latihan, sehingga dengan intensitas latihan banyak akan memberikan hasil yang semakin baik.

\section{SIMPULAN DAN SARAN}

Bersumber pada analisis hasil serta ulasan, bisa disimpulkan kalau terdapat pengaruh signifikan pada pemberian latihan Circuit Training terhadap kenaikan kekuatan raga siswa sekolah sepakbola di SSB Persisac Semarang. Bersumber pada hasil uji t diperoleh nilai thitung (31, 281)

t tabel( 1,761$)$, serta nilai p\&lt; dari 0, 05. Hasil tersebut dimaksud Ho diterima, sehingga hipotesisnya melaporkan terdapat pengaruh latihan Circuit Training terhadap kenaikan kekuatan raga siswa sekolah sepakbola di SSB Persisac Semarang.

Hasil riset ini bisa dijadikan selaku salah satu tolak ukur dalam menyusun program latihan spesialnya tentang modul buat tingkatkan keadaan raga sepakbola. Hasil riset ini bisa dijadikan motivasi dalam mengejar cita- cita selaku pemain sepakbola professional sebab dengan berlatih secara tekun, semangat serta dengan program latihan yang baik pula, latihan bisa tingkatkan keadaan raga, metode, taktik, serta lain sebagainya.

\section{DAFTAR PUSTAKA}

Achmad Jayul, d. E. (2020). Model Pembelajaran Daring Sebagai Alternatif Proses Kegiatan Belajar Pendidikan Jasmani di Tengah Pandemi Covid-19 (Vol. 6). Banyuwangi: Jurnal Pendidikan Kesehatan Rekreasi.

Agus Purwanto, d. (2020). Studi Eksploratif Dampak Pandemi Covid-19 Terhadap Proses Pembelajaran Online di Sekolah Dasar (Vol. 2). ISSN Online.

Ali Sadikin, d. A. (2020). Pembelajaran Daring di Tengah Wabah Covid-19 (Vol. 6). Jambi: Jurnal Ilmiah Pendidikan Biologi.

Dindin Jamaluddin, d. (2020). Pembelajaran Daring Masa Pandemik Covid-19 Pada Calon Guru: Hambatan, Solusi dan Proyeksi. Bandung.

Harsuki, Ma. (2003). Perkembangan Olahraga Terkini. Jakarta: PT. raja Grafindo Persada

Herlina, A. M. (2020). "Need Analysis of Using Goggle Form For Learning". Jurnal Dikdas.

Kemendikbud. (2020). Surat Edaran No. 4 Tahun 2020 Tentang Peaksanaan Kebijakan Pendidikan Dalam Masa Darurat Penyebaran CORONAVIRUS DISESASE (Covid-19).

KemenPAN-RB. (2020). "Surat Edaran menteri Pemberdayaamn Aparatur Negara Dan Reformasi Birokrasi (MenPAN-RB) Nomor 19 Tahun 2020 Tentang Penyesuaian Sistem Kerja Aparatur Sipil Negara Dalam Upaya Pencegahan Penyebaran Covid-19 Di LIngkungan Instansi Pemerintah".

Medico, B. (2020). Coronavirus Covid-19, Membelah Diri, Cara Menghindari Penularan, Bagaimana Melindungi Keluarga dan Pekerjaan Anda: Manual Pertama untuk Mempertahankan Diri Terhadap Infeksi CoronaVirus.

Nova Erawati Simatupang, d. (2020). Efektivitas Pelaksanaan Pengajaran Online Pada Masa Pandemi Covid-19 Dengan Metode Survey Sederhana (Vol. 13). Jakarta Indonesia: Jurnal Dinamika Pendidikan. 
Pratiwi, E. W. (2020). Dampak Covid-19 Terhadap Kegiatan Pembelajaran Online di Sebuah Perguruan Tinggi Kristen di Indonesia (Vol. 1). Kota Salatiga Jawa Tengah: Perspektif Ilmu Penidikan.

Pujilestari, Y. (2020). Dampak Positif Pembelajaran Online Dalam Sistem Pendidikan Indonesia Pasca Pandemi Covid-19 (Vol. 1). ADALAH.

Siahaan, M. (2020). Dampak Pandemi Covid-19 Terhadap Dunia Pendidikan (1 ed.). Bekasi Utara, Jawa Barat: Jurnal Kajian Ilmiah.

Sugiarto, E. (2015). Menyusun Proposal Penelitian Kualitatif Skripsi dan Tesis. Yogyakarta: Suaka Media.

Sugiyono. (2010). Statistik Untuk Penelitian . Bandung: Alfabeta.

Suparman, A. (2014). Teknologi Pendidikan Dalam Pendidikan Jarak Jauh. Pdf. Jakarta: Universitas Terbuka.

Suryabrata, S. (1983). Metodologi Penelitian . Jakarta : Rajawali Pers. 